\title{
Gastric antral vascular ectasia in a patient with lupus undergoing hemodialysis: a case report
}

\author{
Seok Hui Kang, A Young Kim and Jun Young Do*
}

\begin{abstract}
Background: Gastric antral vascular ectasia (GAVE), associated with autoimmune diseases, such as systemic lupus erythematosus, and hepatic or renal disorders, is a rare cause of gastrointestinal bleeding. We report the case of a patient with lupus erythematosus undergoing hemodialysis with an uncorrectable anemia caused by GAVE.

Case presentation: A 76-year-old Korean woman with lupus undergoing hemodialysis frequently complained of symptoms or signs associated with anemia, such as dizziness, dyspnea, hypotension, melena, and hematemesis. Gastrointerstinal endoscopy revealed multiple erythematous and hyperemic mucosal lesions at the distal antrum without active bleeding, a finding compatible with GAVE. Although she frequently complained of symptoms or signs associated with anemia and had frequent gastrointestinal endoscopies with or without pre-emptive argon plasma coagulation, her clinical status is relatively stable, and she is undergoing maintenance hemodialysis without anticoagulants.
\end{abstract}

Conclusion: This clinical case suggests that GAVE should be considered as a cause of the anemia resistant to erythropoiesis-stimulating agents and iron supplementation in patients with chronic kidney disease and lupus.

Keywords: Gastric antral vascular ectasia, Lupus erythematosus, Hemodialysis, Anemia, Case report

\section{Background}

Anemia is a common complication in patients on hemodialysis (HD) [1]. Almost all patients undergoing maintenance HD have anemia, mainly due to decreased erythropoietin production or a functional or absolute iron deficiency. Other causes of anemia include infections, underdialysis, hyperparathyroidism, and malignancy. Gastrointestinal bleeding can also cause an uncorrectable anemia despite proper supplementation of erythropoietin and iron.

Gastric antral vascular ectasia (GAVE), associated with autoimmune diseases, such as systemic lupus erythematosus (SLE), and hepatic or renal disorders, is a rare cause of gastrointestinal bleeding [2]. Although the pathogenesis of

\footnotetext{
* Correspondence: jydo@med.yu.ac.kr

Department of Internal Medicine, Yeungnam University Hospital, 317-1

Daemyung-Dong, Nam-Ku, Daegu 705-717, South Korea
}

GAVE is not fully understood, it can be an important cause of severe anemia in patients on HD. We report the case of a patient with SLE undergoing HD with an uncorrectable anemia caused by GAVE.

\section{Case presentation}

A 76-year-old Korean woman was admitted to our hospital due to sore throat and poor oral intake. The patient presented with a decreased urine output and a febrile sensation. She had hypertension for 1 year and was taking amlodipine $10 \mathrm{mg} /$ day. She had no history of gastrointestinal, liver, or renal diseases. In addition, she had undergone upper and lower gastrointestinal endoscopies (GFS), which revealed non-significant findings without bleeding lesion.

On admission, the blood pressure was $130 / 70 \mathrm{mmHg}$, with a pulse rate of 80 beats/min. Grade 1 pretibial

\section{$\triangle B M C$}

(c) The Author(s). 2020 Open Access This article is licensed under a Creative Commons Attribution 4.0 International License, which permits use, sharing, adaptation, distribution and reproduction in any medium or format, as long as you give appropriate credit to the original author(s) and the source, provide a link to the Creative Commons licence, and indicate if changes were made. The images or other third party material in this article are included in the article's Creative Commons licence, unless indicated otherwise in a credit line to the material. If material is not included in the article's Creative Commons licence and your intended use is not permitted by statutory regulation or exceeds the permitted use, you will need to obtain permission directly from the copyright holder. To view a copy of this licence, visit http://creativecommons.org/licenses/by/4.0/ The Creative Commons Public Domain Dedication waiver (http://creativecommons.org/publicdomain/zero/1.0/) applies to the data made available in this article, unless otherwise stated in a credit line to the data. 
pitting edema was noted. The laboratory findings were as follows: hemoglobin $8.6 \mathrm{~g} / \mathrm{dL}$ (normal: $12-16 \mathrm{~g} / \mathrm{dL}$ ), platelet count $86,000 / \mathrm{mm}^{3}$, blood urea nitrogen 124.7 $\mathrm{mg} / \mathrm{dL}$ (normal: $10 \sim 20 \mathrm{mg} / \mathrm{dL}$ ), and serum creatinine $8.87 \mathrm{mg} / \mathrm{dL}$ (normal: $0.6 \sim 1.2 \mathrm{mg} / \mathrm{dL}$ ). The 24-h urine protein was $1214 \mathrm{mg} /$ day (urine volume was $1250 \mathrm{cc}$ ). Physical examination revealed a dehydrated tongue and no organomegaly. The rectal examination was negative for melena. Chest radiography and computed tomography showed ground-glass opacity in both lung fields and bilateral pleural effusion. Echocardiography showed a pericardial effusion without regional wall motion abnormalities. Abdominal computed tomography showed non-specific findings; the right and left kidneys were 8.6 and $8.9 \mathrm{~cm}$ in diameter, respectively. Antinuclear antibody (ANA) titer was 1:320. The patient had normal complement level and negative result for anti-dsDNA level. The diagnosis of SLE was performed using 2019 European League Against Rheumatism/American College of Rheumatology classification criteria [3]. The patients had high ANA level (1:320 titre) and SLE was considered. We evaluated additive criteria and the patient had thrombocytopenia $\left(86,000 / \mathrm{mm}^{3}, 4\right.$ score weightage), pleural and pericardial effusion (detected on CT imaging, 5 score weightage), oral ulcer (detected on physical examination and history, 2 score weightage), and proteinuria $(1.4 \mathrm{~g} /$ day at initial findings and sustained $+2 \sim+3$ in urine dipstick test after infectious conditions, 4 score weightage). Total score was 15 and the patient was diagnosed with SLE [3]. The patient had pleural and pericardial effusions, but had decreased effective circulating volume. Therefore, fluid therapy and antibiotics were initiated due to upper respiratory infection symptoms and signs. The serum creatinine level recovered to $3.9 \mathrm{mg} / \mathrm{dL}$ at 1 month after hospitalization, when the patient was discharged. The serum creatinine improved to $3.03 \mathrm{mg} / \mathrm{dL}$ at 2 months after first visit. Prednisolone $10 \mathrm{mg}$ per day and hydroxylchloroquine sulfate $400 \mathrm{mg}$ per day were started 3 months after first visit.

She was followed up for 16 months at the outpatient department and hemoglobin level was stable during first 16 months using erythropoiesis stimulating agent (ESA) and oral iron supplementation. However, at 17 months after the first visit, the serum creatinine level steadily increased and the anemia was refractory to the erythropoiesisstimulating agent and iron supplementation treatment. At the outpatient department, the laboratory findings revealed blood urea nitrogen, serum creatinine, and hemoglobin levels of $103 \mathrm{mg} / \mathrm{dL}, 6.1 \mathrm{mg} / \mathrm{dL}$, and $9.0 \mathrm{~g} / \mathrm{dL}$, respectively. She was started on HD through a tunneled cuff catheter and underwent surgery for autologous arteriovenous fistula creation. Hemoglobin level was relatively stable after initiation of HD. We thought that the cause of anemia at the initiation of HD was uremia.

After 5 months from initiation of HD, hemoglobin level suddenly dropped to $5.5 \mathrm{~g} / \mathrm{dL}$ and the patient complaint of dizziness and did not have change in stool nature. The anemia was evaluated using the iron status, peripheral blood (PB) smear, and GFS. Iron, transferrin saturation, and ferritin levels were $46 \mu \mathrm{g} / \mathrm{dL}, 18.5 \%$, and $448.5 \mathrm{ng} / \mathrm{mL}$ (reference level: $5-205 \mathrm{ng} / \mathrm{mL}$ ), respectively. The PB smear revealed a normocytic normochromic anemia. GFS revealed multiple erythematous raised hyperemic mucosal lesions at the distal antrum without active bleeding (Fig. 1), a finding compatible with GAVE. Anti-ulcer treatment was started using a proton pump inhibitor. Although the patient was diagnosed with GAVE, the patient did not have active bleeding focus and melena. We performed bone marrow biopsy because the definite cause of anemia was not identified. The bone marrow biopsy showed a normocellular marrow with normal iron status. Hemoglobin level was stable after transfusion and anemia did not recur.

At 9 months after initiation of HD, the patient firstly complaint of melena and emergency GFS was performed. The GFS revealed active bleeding lesion at GAVE. Bleeding focus was treated using argon plasma coagulation (APC). The hemoglobin level was stable after the treatment of GAVE. However, after first diagnosis of bleeding at GAVE, she frequently complained of symptoms or signs associated with anemia, such as dizziness, dyspnea, hypotension, melena, and hematemesis. During 18 months after the diagnosis of GAVE, she underwent four pre-emptive APC treatments for the GAVE lesions expected to bleed and four APC treatments for actively bleeding lesions. Although she frequently complained of symptoms or signs associated with anemia and had frequent GFSs with or without APC, her clinical status is relatively stable, and she is undergoing maintenance HD without anticoagulants.

\section{Discussion and conclusion}

We wanted to present a case with multiple risk factors for GAVE, such as advanced chronic kidney disease (CKD) and SLE, and importance of repeated GFS in patients with multiple risk factors. Our case reveal that GAVE developed between first visit and 5 months after initiation of HD. Although anemia was presented at the initiation of HD, anemia was corrected after initiation of HD. We diagnosed anemia caused by uremia and did not perform repeated GFS. We definitely diagnosed GAVE at 5 months after initiation of HD. However, at first visit, GFS at local medical center may be misdiagnosed to erosive gastritis, which can be difficult to differentiate from GAVE in some cases [4,5]. At 5 months after initiation of $\mathrm{HD}$, hemoglobin level suddenly 


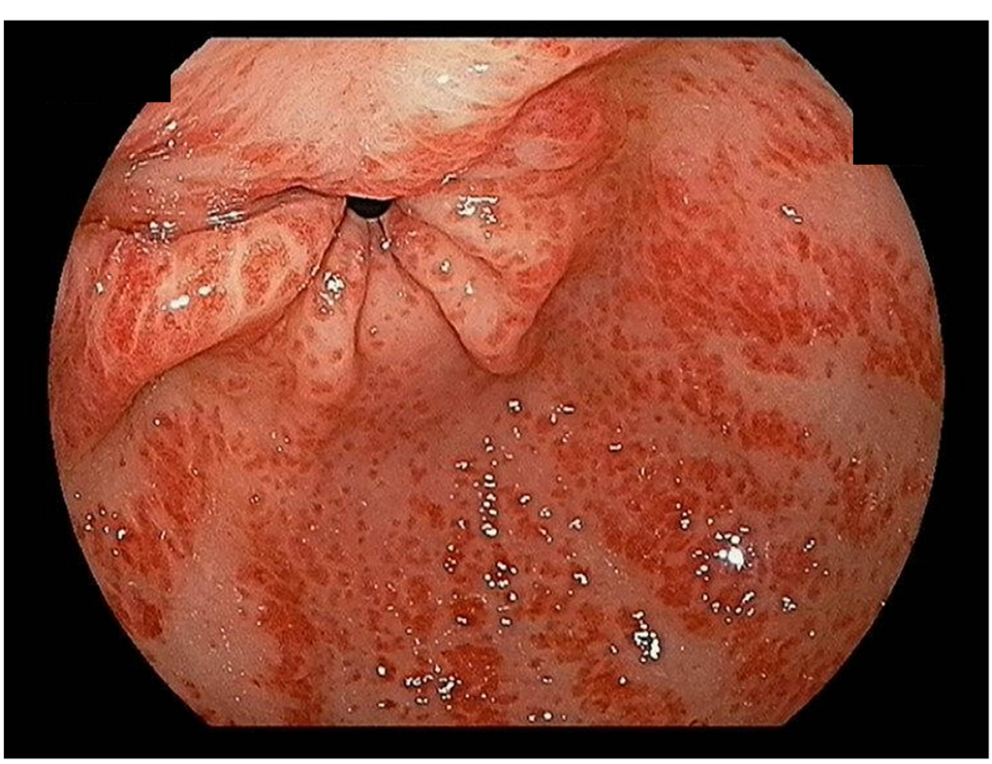

Fig. 1 Gastrointestinal endoscopy revealed multiple erythematous and hyperemic mucosal lesions at the distal antrum without active bleeding, a finding compatible with gastric antral vascular ectasia

decreased, but bleeding from GAVE and melena were not observed. Therefore, we performed bone marrow biopsy. The cause of anemia at this point may be occult bleeding from GAVE, but the patient's hemoglobin level was normalized after transfusion and stable hemoglobin level was maintained using proper ESA and iron therapy. Significant first bleeding in GAVE developed at 9 months after the initiation of HD. These findings reveal that GAVE can be misdiagnosed with diseases such as erosive gastritis and repeated GFS should be considered in patients with anemia, multiple risk factors of GAVE, and refractory to resistant to ESAs and iron, although recent performed GFS did not show GAVE.

GAVE was first reported by Rider et al., characterized with longitudinal streaks of erythematous mucosa, termed as watermelon stomach based on the striped appearance [6]. Previous studies suggested that GAVE is an acquired disease that can be caused by mechanical stress, such as portal hypertension, hormones, such as gastrin, CKD, and connective tissue disease [7].

CKD is one of the commonest health problems [1]. Patients with CKD are prone to anemia due to many factors, and gastrointestinal bleeding should be excluded. GAVE is a rare cause of anemia in these patients. A previous report suggested that the relationship between GAVE and CKD is associated with abnormalities of the gastric emptying and antral motility, vasoactive mediators, and increased gastrin levels [8]. The treatment of GAVE in patients with CKD is same as that in patients without CKD. Repeated endoscopic coagulation is important regardless of the etiology. In previous reports, patients were treated using various methods, such as APC, laser coagulation, gastrectomy, or electrocoagulation.
GAVE in patients with CKD was most commonly reported in the Japanese elderly population $[9,10]$.

Autoimmune disorders are co-present in $60 \%$ of the patients with GAVE [2]. Many of these patients have autoantibodies. Although the association between the autoantibodies and GAVE as a pathogenesis of the disease is obscure, some investigators showed crossreactivity of the autoantibodies with the gastric vessels $[11,12]$. In our case, she had autoantibodies and CKD as risk factors of GAVE. She did not respond to ESA and iron supplementation treatment. Repeated APCs were needed to control the anemia and/or bleeding. GAVE in patients with lupus undergoing HD is even more rare. Jinga et al. reported a case of GAVE in a patient on peritoneal dialysis who had lupus [13]. To the best of our knowledge, this is the first report in Korea population.

No renal pathologic finding is an important limitation in our study. Renal biopsy should be considered for definite diagnosis of lupus nephritis, but we thought that renal pathologic finding would be not essential for future treatment plan or patient prognosis, considering risks of renal biopsy or use of strong immunosuppressants due to old age and poor general conditions. In addition, the patient refused renal biopsy. The patient can be diagnosed with renal disease by either immune or non-immune mediated injuries. The patient had normal complement level and negative result for antidsDNA level. We suggest that the patient had acute kidney injury on CKD regarding clinical course and laboratory findings. CKD in this case could be associated with nonimmunologic injuries alone, immunologic injuries regardless of lupus, or non-immunologic injuries comined with nonactive lupus nephritis rather than active lupus nephritis per 
se $[14,15]$. Acute kidney injury may be associated with nonimmunologic problems due to improvement by conservative treatment alone. In our case, immunosuppressants were started 3 months after first visit, but the serum creatinine improved from $8.87 \mathrm{mg} / \mathrm{dL}$ at first visit to $3.03 \mathrm{mg} / \mathrm{dL}$ at 2 months after first visit.

Two factors in HD patients can cause difficulty in diagnosis and treatment of gastrointestinal bleeding, such as GAVE. First, CKD is well-known as a category of anemia of chronic disease with high ferritin and low transferrin saturation levels [16]. Iron deficiency status as a manifestation of bleeding can be hidden due to underlying high ferritin and low transferrin saturation levels. The patient had high serum ferritin level from first visit to first bleeding. The relatively high ferritin level at first bleeding would be associated with combination of anemia of chronic disease and bleeding. However, serum ferritin level decreased to $71.34 \mathrm{ng} / \mathrm{mL}$ at 2nd bleeding from GAVE, inspite of oral iron therapy. C-reactive protein level was high at first visit (13.615 $\mathrm{mg} / \mathrm{dL}$ ), the level was normal at 1 month after initial first visit $(0.19 \mathrm{mg} / \mathrm{dL})$ and the $\mathrm{C}$-reactive protein level was stable throughout the clinical course. These findings reveal that high ferritin and low transferrin saturation levels were associated with anemia of chronic disease by CKD (not for acute inflammatory status). Second, most HD patients are prone to anemia and require ESAs and iron supplementation [16]. Oral iron supplementation is associated with dark stool, which lead to difficulty in identifying grossly melena and false positive for stool occult blood test. If bleeding from gastrointestinal lesion was insidious, hemoglobin level will decrease slowly. The clinician may first consider increase in dose of ESAs rather than evaluation of bleeding. The clinician may consider gastrointestinal bleeding as a cause of anemia in unusual high dose of ESA or sudden large decrease in hemoglobin level.

This clinical case suggests that GAVE should be considered as a cause of the anemia resistant to ESAs and iron supplementation in patients with CKD and lupus.

\section{Abbreviations \\ ANA: Antinuclear antibody; CKD: Chronic kidney disease; GAVE: Gastric antral vascular ectasia; GFS: Gastrointestinal endoscopies; ESA: Erythropoiesis stimulating agent; HD: Hemodialysis; PB: Peripheral blood; APC: Argon plasma coagulation}

\section{Acknowledgements}

Not applicable.

\section{Authors' contributions}

SHK contributed the conception, design of the work, the acquisition, analysis; SHK, JYD, and AYK performed interpretation of data and drafted the work; SHK and JYD approved the submitted version. All authors agreed both to be personally accountable for the author's own contributions and to ensure that questions related to the accuracy or integrity of any part of the work, even ones in which the author was not personally involved, are appropriately investigated, resolved, and the resolution documented in the literature.

\section{Funding}

This work was supported by the 2017 Yeungnam University Research Grant Funder had no role in study design; the collection, analysis and interpretation of data; the writing of the report; and the decision to submit the article for publication.

\section{Availability of data and materials Not applicable.}

\section{Ethics approval and consent to participate}

This study received ethical approval from the institutional review board of Yeungnam University Medical Center. Written informed consent was obtained from the patient for publication of this Case Report and any accompanying images and videos. A copy of the written consent is available for review by the Editor of this journal.

\section{Consent for publication}

Informed consent was obtained from the patient.

\section{Competing interests}

Nothing to declare.

Received: 16 March 2020 Accepted: 30 October 2020

Published online: 10 November 2020

\section{References}

1. National Kidney Foundation. K/DOQI clinical practice guidelines and clinical practice recommendations for anemia in chronic kidney disease. Am J Kidney Dis. 2006:47:S1-S146.

2. Fuccio L, Mussetto A, Laterza L, Eusebi LH, Bazzoli F. Diagnosis and management of gastric antral vascular ectasia. World J Gastrointest Endosc. 2013;5:6-13.

3. Aringer M, Costenbader K, Daikh D, Brinks R, Mosca M, Ramsey-Goldman R, Smolen JS, Wofsy D, Boumpas DT, Kamen DL, Jayne D, Cervera R, Costedoat-Chalumeau N, Diamond B, Gladman DD, Hahn B, Hiepe F, Jacobsen S, Khanna D, Lerstrøm K, Massarotti E, McCune J, Ruiz-Irastorza G, Sanchez-Guerrero J, Schneider M, Urowitz M, Bertsias G, Hoyer BF, Leuchten N, Tani C, Tedeschi SK, Touma Z, Schmajuk G, Anic B, Assan F, Chan TM, Clarke AE, Crow MK, Czirják L, Doria A, Graninger W, Halda-Kiss B, Hasni S, Izmirly PM, Jung M, Kumánovics G, Mariette X, Padjen I, Pego-Reigosa JM, Romero-Diaz J, Rúa-Figueroa Fernández Í, Seror R, Stummvoll GH, Tanaka Y, Tektonidou MG, Vasconcelos C, Vital EM, Wallace DJ, Yavuz S, Meroni PL, Fritzler MJ, Naden R, Dörner T, Johnson SR. 2019 European league against rheumatism/American College of Rheumatology classification criteria for systemic lupus erythematosus. Ann Rheum Dis. 2019;78:1151-9.

4. Yüksel O, Köklü S, Başar O, Yüksel I, Akgül H. Erosive gastritis mimicking watermelon stomach. Am J Gastroenterol. 2009:104:1606-7.

5. Saadah Ol. Erosive gastritis mimicking watermelon stomach in a child. Arab J Gastroenterol. 2011;12:201-2.

6. Rider JA, Klotz AP, Kirsner JB. Gastritis with veno-capillary ectasia as a source of massive gastric hemorrhage. Gastroenterol. 1953;24:118-23.

7. Smith E, Davis J, Caldwell S. Gastric Antral vascular Ectasia pathogenesis and the link to the metabolic syndrome. Curr Gastroenterol Rep. 2018;20:36.

8. Stefanidis I, Liakopoulos V, Kapsoritakis AN, loannidis I, Eleftheriadis T, Mertens PR, Winograd R, Vamvaka E, Psychos AK, Potamianos SP. Gastric antral vascular ectasia (watermelon stomach) in patients with ESRD. Am J Kidney Dis. 2006:47:e77-82.

9. Io H, Takeda Y, Okumura K, Sakamoto N, Obayashi K, Suzuki S, Funabiki K, Horikoshi S, Shirato I, Tomino Y. A case of gastric antral vascular ectasia (GAVE) with chronic renal failure. Nihon Jinzo Gakkai Shi. 2001;43:82-7.

10. Iguchi A, James Kazama J, Komatsu M, Kaneko Y, lino N, Goto S, Narita I. Three cases of gastric antral vascular ectasia in chronic renal failure. Case Rep Nephrol Urol. 2011;1:15-9.

11. Garcia MC, Zhou J, Henning D, Arnett FC, Valdez BC. Unique epitopes in RNA helicase II/Gu protein recognized by serum from a watermelon stomach patient. Mol Immunol. 2000;37:351-9.

12. Valdez BC, Henning D, Busch RK, Woods K, Flores-Rozas H, Hurwitz J, Perlaky $\mathrm{L}$, Busch $\mathrm{H}$. A nucleolar RNA helicase recognized by autoimmune antibodies 
from a patient with watermelon stomach disease. Nucleic Acids Res. 1996; 24:1220-4.

13. Jinga $M$, Checheriță IA, Becheanu $G$, Jinga V, Peride I, Niculae A. A rare case of watermelon stomach in woman with continuous ambulatory peritoneal dialysis and systemic lupus erythematosus. Romanian J Morphol Embryol. 2013;54:863-5.

14. Maria NI, Davidson A. Protecting the kidney in systemic lupus erythematosus: from diagnosis to therapy. Nat Rev Rheumatol. 2020;16:255-67.

15. Falasinnu T, O'Shaughnessy MM, Troxell ML, Charu V, Weisman MH, Simard JF. A review of non-immune mediated kidney disease in systemic lupus erythematosus: a hypothetical model of putative risk factors. Semin Arthritis Rheum. 2020;50:463-72.

16. KDIGO Anemia Work Group. KDIGO clinical practice guideline for Anemia in chronic kidney disease. Kidney Int Suppl. 2012;2:279-335.

\section{Publisher's Note}

Springer Nature remains neutral with regard to jurisdictional claims in published maps and institutional affiliations.

Ready to submit your research? Choose BMC and benefit from:

- fast, convenient online submission

- thorough peer review by experienced researchers in your field

- rapid publication on acceptance

- support for research data, including large and complex data types

- gold Open Access which fosters wider collaboration and increased citations

- maximum visibility for your research: over $100 \mathrm{M}$ website views per year

At BMC, research is always in progress.

Learn more biomedcentral.com/submissions 